\title{
Myositis in father and daughter
}

\author{
R. M. LEWKONIA ${ }^{1}$ AND P. H. BUXTON \\ From the Royal Southern Hospital, Liverpool and the Neuropathology Laboratory, \\ Regional Department of Medical and Surgical Neurology, Walton Hospital, Liverpool
}

SUMMARY The occurrence of myositis in a father and his daughter is reported. The daughter's illness resembled childhood dermatomyositis and progressed to systemic involvement and death less $\frac{\bar{\sigma}}{\sigma}$ than four years from the onset of symptoms. In the case of the father the illness followed the course $\stackrel{\mathbb{Q}}{2}$ of adult polymyositis and there was little evidence of systemic involvement. The immunological and $\%$ genetic significance of the two cases is discussed.

The close relationship between polymyositis and dermatomyositis has been apparent since Wagner (1887) reported a case of polymyositis with associated skin lesions. Pearson (1959) regarded the two diseases as clinical variants of a pathological entity and noted that on occasion one blends imperceptibly into the other. Dermatomyositis may, however, be distinguished by its associations. In adults there is a well-established association between dermatomyositis and malignancy (Curtis et al., 1952). In children dermatomyositis is often accompanied by abdominal symptoms (Cook et al., 1963), which have been attributed to a characteristic systemic angiopathy (Banker and Victor, 1966).

This report describes the occurrence of childhood dermatomyositis in the daughter of a patient with adult polymyositis and is further evidence of the close relationship between the diseases. Proximal limb weakness was a major symptom in both cases and muscle biopsy confirmed that the pathology was myositic in nature and not a hereditary muscular dystrophy.

\section{CASE 1}

J.H. presented in 1961, aged 25 years, with an indefinite five year history of pains in and around his shoulder girdle, which had been labelled 'fibrositis', general tiredness, and weight loss. The only physical abnormalities at that time were a persistent low grade fever and a palpably enlarged spleen. Investigations showed the following: erythrocyte sedimenta-

1 Present address: Nuffield Unit of Medical Genetics, Department of Medicine, University of Liverpool. tion rate (ESR) $27 \mathrm{~mm} /$ hour (Wintrobe), total white cell count 10,000 per $\mathrm{cu}$. mm with 5,300 lymphocytes per cu. $\mathrm{mm}$, total serum protein $9 \mathrm{~g} / 100 \mathrm{ml}$., $\dot{\omega}$ globulin $5.9 \mathrm{~g} / 100 \mathrm{ml}$. The bone marrow showed an excess of lymphocytes with some abnormal formฐ In the absence of any definite diagnosis no actip $N$ treatment was given. He was able to continue work 을 ing as a ship's scaler until 1964 when he complaine of general tiredness as before but no further abno 0 mality was found on investigation. In 1966, he ro 0 ? turned complaining of rheumatic pains in his lime and of stiffness in his hands. At this stage late agglutination tests for rheumatoid disease and an $\overrightarrow{0}$ nuclear factors were positive and lupus erythemato- $\omega$ sus (LE) cells were demonstrated in the blood on one occasion only. A diagnosis was made of systemic lupus erythematosus (SLE) and treatment with prednisolone was started. There was little symptomatic improvement and he became depressed to the $\mathbb{D}$ extent of requiring psychiatric treatment. LE cells $\Rightarrow$ were demonstrated once more early in 1968, but late in 1968 investigations at another hospital showed no evidence of SLE and the steroid treatment was stopped. He experienced increasing muscular weakness early in 1969 and when seen again in April 1970 he had profound proximal weakness with gross wasting of the limb girdle muscles. The serum creatine phosphokinase level was $506 \mathrm{u} . / 100 \mathrm{ml}$. (normal range 3-60 u.) and electromyography showed profuse fibrillation potentials and other features suggesting polymyositis.

Other investigations were as follows: ESR $\frac{D}{2}$ $4 \mathrm{~mm} /$ hour, bone marrow infiltrated with lymphocytes and abnormal mononuclear cells, serum IgG N $2,400 \mathrm{mg} / 100 \mathrm{ml}$. (normal range $470-1,600 \mathrm{mg}$ ) $100 \mathrm{ml}$.). IgA $630 \mathrm{mg} / 100 \mathrm{ml}$. (120-420 mg/100 ml.), ㅇ IgM $108 \mathrm{mg} / 100 \mathrm{ml}$. (47-170 mg/100 ml.). Anti- $\omega$ 


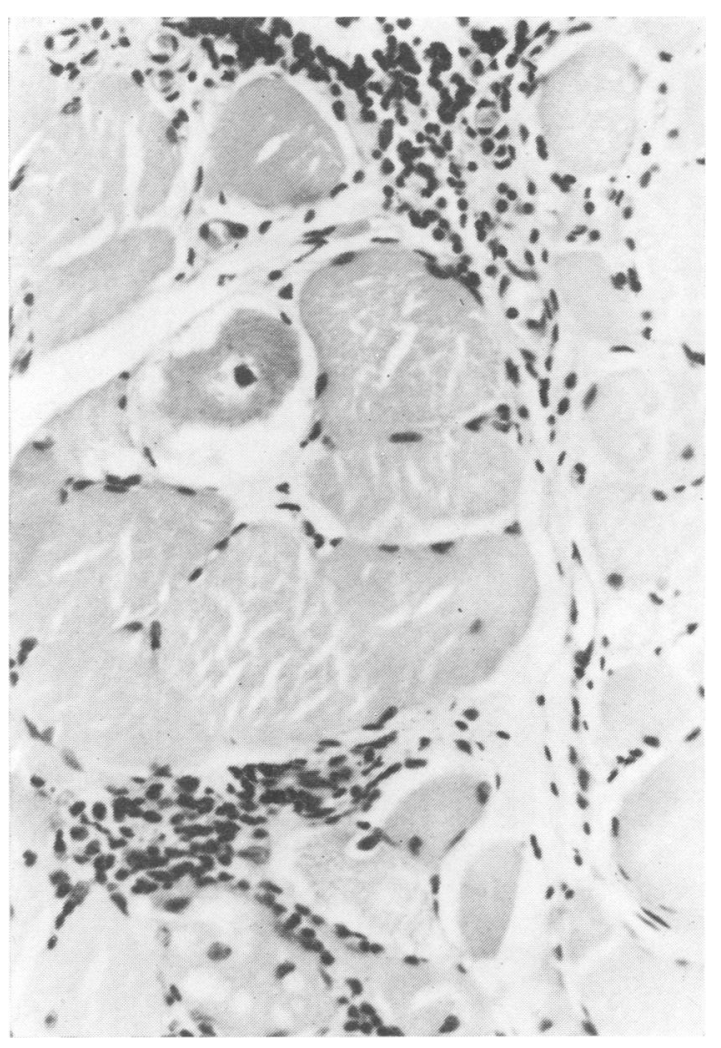

FIG. 1. Muscle biopsy of J.H., showing irregularity of muscle fibre size, fibres with central nuclei, collections of lymphocytes. $H$ and $E, \times 350$.

nuclear factor was not present in the serum and LE cells were not demonstrated.

Muscle biopsy from the right palmaris longus muscle showed considerable variation in muscle fibre size, many muscle fibres had central nuclei (Fig. 1). Occasional regenerating basophil fibres with large central nuclei were seen. There were several large clumps of lymphocytes between muscle fibres and a definite increase in collagen between muscle fibres. Lymphocytic clusters were often related to blood vessels, but no significant arteritis was noted. Stains for phosphorylase and diphosphopyridine nucleotide diaphorase showed a normal complementary pattern. There was no excess of one fibre type. Motor endplate stains showed some branching of terminal nerve fibres and thin irregular terminal expansions.

A confident diagnosis of subacute myositis was made at this stage.

Treatment with prednisolone was reinstituted

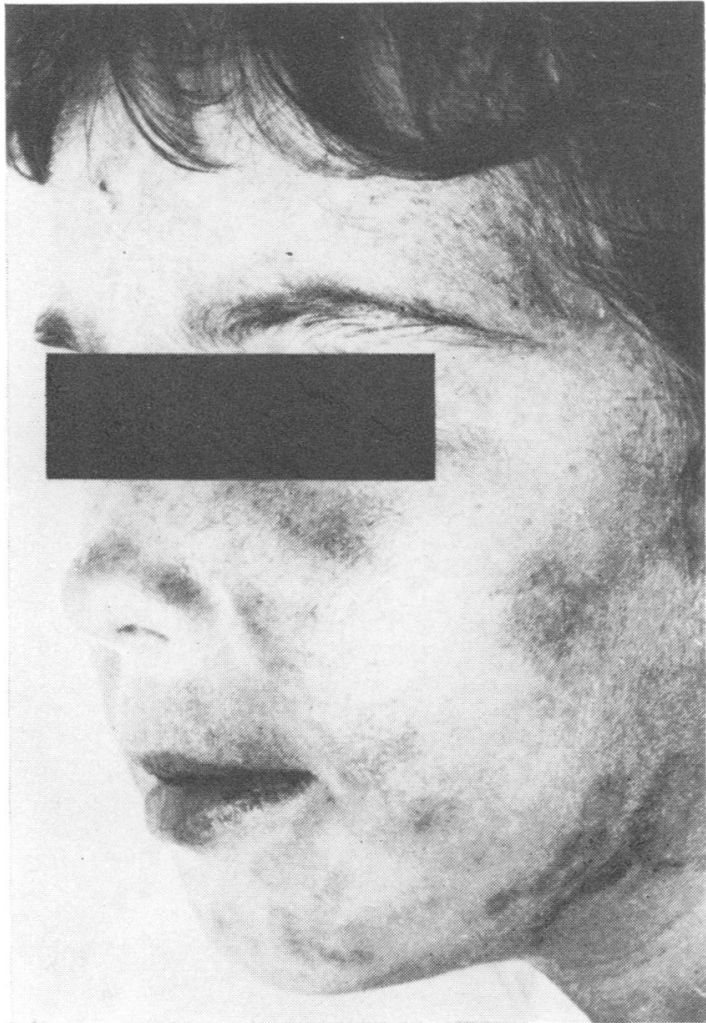

FIG. 2. Facial rash of L.H. at onset of symptoms.

with an initial symptomatic improvement in muscle strength and fall in the serum creatine phosphokinase level. However, there was subsequent deterioration and high dosage prednisolone treatment, azathioprine, and methotrexate were used without clinical improvement.

In the residual state J.H. has profound muscular weakness with inability to climb stairs or to rise unaided from a chair. There has been no evidence of involvement of skin, kidneys, or serosal surfaces at any time and the initial diagnosis of systemic lupus erythematosus has not been validated.

Serological tests for common viral infections and Australia antigen were negative. Culture of the bone marrow for viruses was not helpful and a second muscle biopsy specimen examined by electron microscopy showed no virus particles.

CASE 2

L.H., the daughter of J.H., presented in 1967 aged 9 


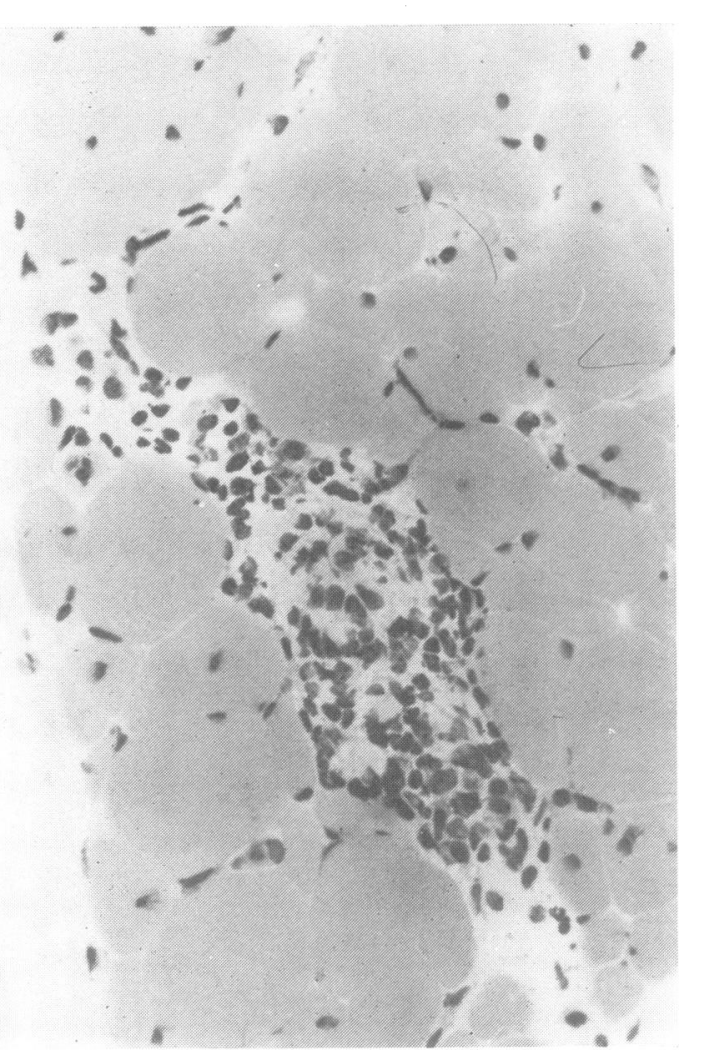

FIG. 3. Muscle biopsy of L.H., showing occasional muscle fibres with central nuclei, collection of inflammatory cells between muscle fibres. $H$ and $E, \times 350$.

years with a facial rash and 'tired legs'. She had periorbital erythema (Fig. 2) and a scaly erythematous rash on her forearms and the dorsum of her fingers: there was no muscle tenderness initially. Investigations showed ESR $80 \mathrm{~mm} /$ hour white cell count 7,000 per cu. $\mathrm{mm}$ with 3,780 lymphocytes per cu. $\mathrm{mm}$, serum alanine aminotransferase $170 \mathrm{u}$. (normal up to $100 \mathrm{u}$.) Latex agglutination tests for rheumatoid and antinuclear factors were negative and LE cells could not be demonstrated. A skin biopsy showed dermal oedema and some thickening of arteriolar walls. There was no abnormality on electromyography. A diagnosis of dermatomyositis was made and treatment was started with prednisolone $15 \mathrm{mg}$ daily. The erythema faded and the serum transaminase level fell to normal. Late in 1967 antinuclear factor was demonstrated in the serum at a dilution of 1 in 1,000. Treatment was maintained with prednisolone $2.5 \mathrm{mg}$ daily and she was clinically well for several months. In June 1969 she again complained of difficulty in walking and of pains in her

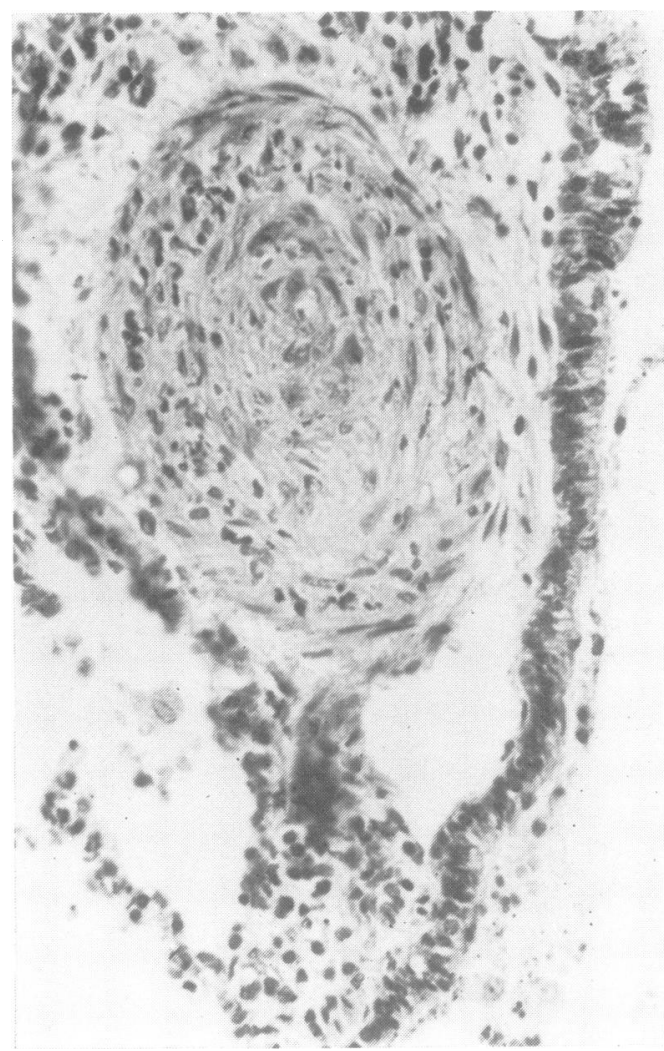

FIG. 4. Pulmonary arteriole showing gross thicken of intima and occlusion by thrombus. $H$ and $E, \times 350$.

legs. Her muscles felt firm and she had enlarged lymph nodes in the neck, axillae, and inguinab regions, bilateral parotid enlargement, and hepato 0 splenomegaly. A lymph node biopsy showed norma $\overrightarrow{5}$ histological appearances and a Kveim test was negative. The dose of prednisolone was increased to $60 \mathrm{mg}$ daily with subsequent clinical improvement. and regression of the hepatic and splenic enlarges ment. Remission of symptoms was maintained wit? prednisolone $10 \mathrm{mg}$ daily until April 1970 whero complaints of breathlessness and chest pain werę. associated with a pericardial friction rub and radio 8 logical evidence of pericardial and pleural effusions The pericarditis settled after an increase in the dose of prednisolone. In November 1970 she was unable to climb stairs because of weakness in her legs and she became breathless on exertion. There was cardiac gallop rhythm and an apical systolic muro mur. Many of her joints were stiff, although not swollen. In addition, periorbital oedema, bilateraㅐ parotid swelling, and hepatosplenomegaly were agaige 
well marked. Electromyography showed profuse fibrillation potentials and low voltage polyphasic potentials on movement. Muscle biopsy, taken from the left palmaris longus muscle at the same time as an open liver biopsy was being performed, showed variation in size of muscle fibres, due mainly to the presence of scattered small fibres; many fibres were seen with central nuclei (Fig. 3).

A collection of lymphocytes was seen in one section, but there was no extensive inflammatory cell infiltrate and no gross change in interstitial tissue. Motor endplate stains showed some evidence of mild denervation change. Sections of skin showed collections of inflammatory cells in the lower dermis and some increase in collagen. It was concluded that these changes were entirely compatible with a diagnosis of dermatomyositis.

The child was allowed home after the biopsies but she died suddenly a few days later.

At necropsy the heart was dilated and hypertrophied, particularly on the right side; there were bilateral pleural effusions, ascites, an enlarged haemorrhagic liver, and enlarged salivary glands. Histology of the liver showed central venous congestion and inflammatory infiltrates in the portal tracts. The salivary glands and cervical lymph nodes showed extensive infiltration with plasma cells. Thickening of the pulmonary arterial walls was found similar to the appearances in primary pulmonary hypertension (Fig. 4). There was no abnormality in the kidneys on light microscopy.

FAMILY BACKGROUND J.H. is descended from West African and Caucasian parents, his wife is not consanguineous and there is no other family history of muscular, rheumatic, or allergic disorder. Three other children of J.H., aged 12 years, 8 years, and 2 years, are clinically well, as is his only brother. All of these members of the family were screened for antinuclear and rheumatoid factors with negative findings. Their muscle enzyme levels and serum electrophoretic patterns were normal.

\section{DISCUSSION}

The polymyositic disorders have been classified into three groups by the Research Group on Neuromuscular Disorders (1968) as follows:

Alpha Polymyositis occurring as an organ specific autoimmune disease.

Beta Polymyositis or dermatomyositis occurring as one feature of a non-organ specific autoimmune disease.

Gamma Polymyositis or dermatomyositis occurring in association with malignant disease.
Despite the history of some 15 years, the clinical abnormalities in the case of the father, J.H., have been virtually confined to his muscles. However, the demonstration of LE cells and antinuclear factor in the serum suggests that the illness of J.H., like that of his daughter, L.H., should be placed within the Beta category.

The illness of L.H. was similar to the picture of childhood dermatomyositis reported by Banker and Victor (1966). In a clinicopathological survey, including eight necropsy studies, they describe a characteristic clinical presentation and claim that the pathological attributes of dermatomyositis of childhood (a systemic angiopathy often causing gastrointestinal lesions) are so unique as to allow its separation from all other connective tissue disorders. L.H. showed necropsy evidence of systemic angiopathy, notably in the lungs. Abnormalities in the pulmonary arterioles have been noted previously in collagen diseases (Wagenvoort et al., 1964). The salivary gland involvement in L.H. was an atypical feature, although it is of interest that J.H. had very high globulin levels and in polymyositis associated with Sjögren's syndrome such high levels are the usual finding (Pearson, 1969). Lymphoma has been described as a complication of Sjögren's syndrome (Talal and and Bunim, 1964) and this may be relevant to the persistent mononuclear cell infiltration of the bone marrow of J.H. Malignant lymphoma was the cause of death in a child with agammaglobulinaemia who developed dermatomyositis (Page et al., 1963).

The occurrence of related disorders in members of the same family may be due to coincidence or to genetic and environmental factors. The annual incidence of polymyositis has been estimated to be between 150 and 200 new cases per annum throughout the United Kingdom (Rose and Walton, 1966); the probability of two cases occurring in the same family unit must, therefore, be very small. Moreover the several similarities in the illnesses of J.H. and his daughter point to a common pathogenesis. Childhood dermatomyositis has been reported in a pair of identical twins (Cook et al., 1963) but familial aggregation in this disease and in adult polymyositis appears to be exceptional as indicated by the paucity of cases in the literature. Familial incidence of systemic lupus erythema- 
tosus has been reviewed by Brunjes, Zike, and Julian (1961), Leonhardt (1967) and by Dubois (1966) who found a family history of the disease in $2 \%$ of a personal series of 512 cases.

Recent reports have raised the possibility that some connective tissue disorders in man may be initiated by infective agents and this could explain familial aggregation of cases. Rheumatoid arthritis has been associated with $\mathrm{Myco}$ plasma fermentans (Williams et al., 1970) and Australia antigenaemia has been associated with both polyarteritis (Gocke et al., 1970) and with systemic lupus erythematosus (Alarçón-Segovia et al., 1972). Cytoplasmic inclusions similar to nucleoprotein strands liberated from myxoviruses have been observed in renal biopsy specimens from patients with SLE (Györkey et al., 1969).

Of particular interest are the reports of Chou (1967) who found aggregates of tubular filaments resembling those of myxovirus groups in muscle biopsies from a patient with polymyositis, and of Mastaglia and Walton (1970) who reported the presence of Coxsackie virus-like particles in skeletal muscle from a case of polymyositis. The relevance of these reports to the majority of cases of polymyositis remains to be established.

The in vitro cytotoxic studies of Currie et al. (1971) have provided evidence that polymyositis is probably caused by a cell mediated autoimmune response directed against muscle antigens. According to Burnet (1959) various kinds of tissue damage could allow the emergence of mutant cell clones with 'forbidden patterns' of activity, which eventually cause a disease state such as autoimmune myositis.

The current theories of pathogenesis may be interpreted in two ways in the context of an apparent inherited susceptibility to an autoimmune disease. There might be a deficiency in the normal ability to eliminate the 'forbidden clones' postulated by Burnet (1959) or, alternatively, there might be a special liability to the consequences of infection with a particular initiating agent. The latter possibility arises from the demonstration that in certain experimental animal situations the specific immune response is under strict genetic control (McDevitt and Benaceraff, 1969).

In the cases described here the genetic defect could be a result of the mixed racial ancestry of
J.H., whose father was West African and whose mother was Caucasian. It has been suggested that there might be some genic imbalance in race crosses since different translocations may have been selected for in different races (Clarke, 1964). This may be the explanation of the exceptional occurrence of myositis in a father and daughter both of whom became deficient in the ability to recognize muscle antigens as 'self'.

We wish to thank Dr. Robert Hughes and Dr. J. Rees Roberts for permission to report the two cases, Professor K. McCarthy for his help with the virological investigations, and Dr. D. Stanley who performed the necropsy examination.

\section{REFERENCES}

Alarçón-Segovia, D., Fishbein, E., and Díaz-Jouanen, E. (1972). Presence of hepatitis-associated antigen in systemic lupus erythematosus. Clinical and Experimental Immunology, 12, 9-19.

Banker, B. Q., and Victor, M. (1966). Dermatomyositis (systemic angiopathy) of childhood. Medicine (Baltimore $)_{0}$ ir 45, 261-289.

Brunjes, S., Zike, K., and Julian, R. (1961). Familial system

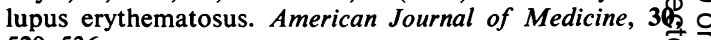
529-536.

Burnet, Sir M. (1959). Auto-immune disease. 2. Pathology $f$ the immune response. British Medical Journal, 2, 720-72

Chou, S. M. (1957). Myxovirus-like structures in a case of chronic human polymyositis. Science, 158, 1453-1455.

Clarke, C. A. (1964). Genetics for the Clinician. 2nd edn, p. 84 Blackwell: Oxford.

Cook, C. D., Rosen, F. S., and Banker, B. Q. (1963\% Dermatomyositis and focal scleroderma. Pediatric Clinics $\omega$ of North America, 10, 979-1016.

Currie, S., Saunders, M., Knowles, M., and Brown, A. E (1971). Immunological aspects of polymyositis. Quarterly Journal of Medicine, 40, 63-84.

Curtis, A. C., Blaylock, H. C., and Harrell, E. R., Jr. (1952). Malignant lesions associated with dermatomyositis. Journal of the American Medical Association, 150, 844-846.

Dubois, E. L. (1966). (Ed.). Lupus Erythematosus, p. 140. McGraw-Hill: New York.

Gocke, D. J., Hsu, K., Morgan, C., Bombardieri, S., Lockshin, M., and Christian, C. L. (1970). Association between polyarteritis and Australia antigen. Lancet, 2, 1149-1153.

Györkey, F., Min, K.-W., Sincovics, J. G., and Györkey, P. (1969). Systemic lupus erythematosus and myxovirus. New England Journal of Medicine, 280, 333.

Leonhardt, E. T. G. (1967). Family studies in systemic lupus erythematosus. Clinical and Experimental Immunology, 2, 743-759.

Mastaglia, F. L., and Walton, J. N. (1970). Coxsackie viruslike particles in skeletal muscle from a case of polymyositis. Journal of the Neurological Sciences, 11, 593-599.

McDevitt, H. O., and Benaceraff, B. (1969). Genetic control 응 of specific immune responses. Advances in Immunology, 11, 31-74.

Page, A. R., Hansen, A. E., and Good, R. A. (1963). Occurrence of leukemia and lymphoma in patients with agammaglobulinemia. Blood, 21, 197-206.

Pearson, C. M. (1959). Rheumatic manifestations of poly- 
myositis and dermatomyositis. Arthritis and Rheumatism, 2, 127-143.

Pearson, C. M. (1969). Polymyositis and related disorders. In Disorders of Voluntary Muscle, 2nd edn., pp. 524-525. Edited by J. N. Walton. Churchill: London.

Research Group on Neuromuscular Disorders (1968). Classification of the neuromuscular disorders. Journal of the Neurological Sciences, 6, 165-177.

Rose, A. L., and Walton, J. N. (1966). Polymyositis: a survey of 89 cases with particular reference to treatment and prognosis. Brain, 89, 747-768.
Talal, N., and Bunim, J. J. (1964). The development of malignant lymphoma in the course of Sjögren's syndrome. American Journal of Medicine, 36, 529-540.

Wagenvoort, C. A., Heath, D. A., and Edwards, J. E. (1964). The Pathology of the Pulmonary Vasculature, p. 96. Thomas: Springfield, Ill.

Wagner, E. (1887). Ein Fall von akuter Polymyositis. Deutsches Archiv fïr Klinische Medicin, 40, 241-266.

Williams, M. H., Brostoff, J., and Roitt, I. M. (1970), Possible role of Mycoplasma fermentans in pathogenesis of rheumatoid arthritis. Lancet, 2, 277-280. 